\title{
MENCARI PERLUASAN MODEL DINAMIK UNSUR-UNSUR UTAMA IKLIM
}

\author{
Agus Indra Jaya ${ }^{1}$ \\ 1Jurusan Matematika FMIPA UNTAD Kampus Bumi Tadulako Tondo Palu
}

\begin{abstract}
Abstrak
Perluasan model dinamik unsur-unsur utama iklim dilakukan dengan mempertimbangkan kemunculan parameter laju perubahan kalor di atmosfer sebagai penentu kestabilan sistem di sekitar titik kritisnya. Perluasan dilakukan dengan melibatkan model konsentrasi gas CO2 kedalam model utama yakni model dinamik unsur-unsur utama iklim berdasarkan hukum termodinamika. Hasil penelitian menunjukkan bahwa model fisibel yang dihasilkan memiliki dua kriteria penentu kestabilan sistem, yakni laju perubahan kalor dan tingkat produksi CO2 yang berkaitan erat dengan tingkat konsumsinya. Perubahan kalor harus melebihi suatu nilai yang dinyatakan dalam fungsi kapasitas panas pada tekanan tetap. Sedangkan tingkat konsumsi gas $\mathrm{CO} 2$ disyaratkan untuk melebihi tingkat produksi.
\end{abstract}

Kata Kunci : model dinamik, parameter, titik kritis, kestabilan sistem

\section{Pendahuluan}

Model dinamik unsur-unsur utama iklim, yakni suhu dan tekanan udara, dibangun oleh system persamaan diferensial yang almost linier yang dibangun berdasarkan kaidah termodinamika. Perilaku sistem yang tidak stabil di sekitar titik kritisnya menujukkan bahwa pola perubahan iklim akan terjadi secara signifikan. Pengamatan terhadap kestabilan sistem dapat dilakukan melalui pengamatan terhadap parameter laju perubahan kalor (Jaya, 2010).

Mengingat laju perubahan kalor di atmosfer sangat berkaitan erat dengan konsentrasi gas $\mathrm{CO}_{2}$ maka model dinamik unsur-unsur utama iklim dapat diperluas dengan meninjau model konsentrasi gas tersebut. Perluasan model perlu mempertimbangkan keterkaitan variablevariabel pembangun sedemikian hingga interaksi antara suhu, tekanan udara dan konsentrasi gas $\mathrm{CO}_{2}$ pada perluasan model tetap mempertahankan peran penting laju perubahan kalor sebagai salah satu indicator kestabilan sistem.

Pencarian perluasan model dinamik unsur-unsur utama iklim yang dikaitkan dengan model konsentrasi gas $\mathrm{CO}_{2}$ dilakukan dengan mengamati system yang dibangun oleh kombinasikombinasi yang mungkin dari kedua model pembangun. Pengamatan terhadap kombinasikombinasi yang muncul selalu mempertimbangkan keterkaitan secara dinamis antara suhu sebagai salah satu unsur utama iklim dengan tekanan udara sebagai unsur utama iklim lainnya. Keterkaitan dinamis tersebut dianggap dipengaruhi oleh perubahan konsentrasi gas $\mathrm{CO}_{2}$ di atmosfer.

\section{Metoda Penelitian}

Pencarian perluasan model dinamik unsur-unsur utama iklim dikaji dengan prosedur sebagai berikut : 
1. Meninjau model dinamik unsur-unsur utama iklim berdasarkan hukum termodinamika

2. Meninjau model konsentrasi gas $\mathrm{CO}_{2}$ di atmosfer

3. Membuat kombinasi model dinamik unsur-unsur utama iklim berdasarkan hukum termodinamika dan model konsentrasi gas $\mathrm{CO}_{2}$ di atmosfer

4. Mengamati kemunculan parameter laju perubahan kalor pada model-model yang dihasilkan oleh langkah 3

5. Memilih model fisibel berdasarkan syarat yang diperoleh pada masing-masing kombinasi yang dihasilkan pada langkah 4

Dasar perluasan model dinamik unsur-unsur utama iklim digambarkan dalam diagram alir berikut :

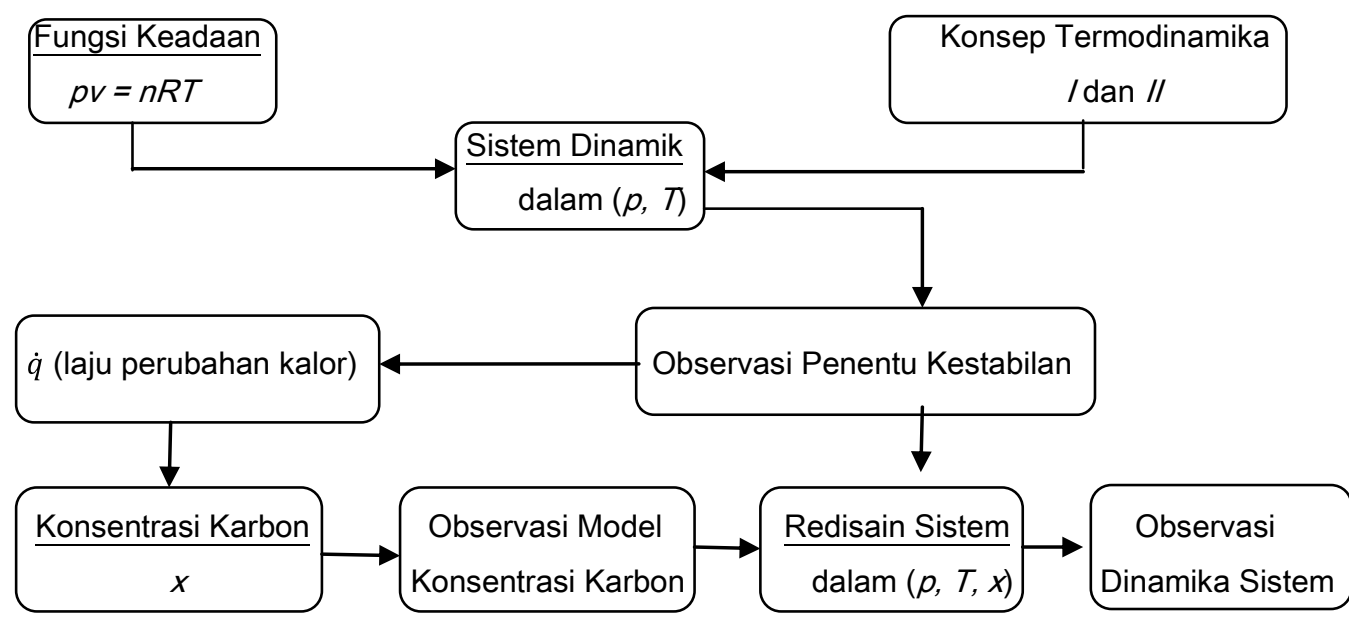

\section{Pembahasan}

\section{1 Model Dinamik Unsur-Unsur Utama Iklim Berdasarkan Hukum Termodinamika}

Persamaan pembangun model dinamik unsur-unsur utama iklim berdasarkan hukum termodinamika dinyatakan dalam (Jaya, 2010) sebagai berikut :

$$
\begin{aligned}
& \dot{T}=\frac{\dot{q}\left[\alpha p \dot{q}+C_{p}-T \dot{q}\right]}{C_{p}\left[C_{p}-K \alpha-\dot{q}\right]} \\
& \dot{p}=\frac{\dot{q}[K-p \dot{q}]}{\left[C_{p}-K \propto-\dot{q}\right]}
\end{aligned}
$$

dengan $\mathrm{T}$ adalah suhu (dalam K), $\mathrm{p}$ adalah tekanan udara (dalam atm), $\dot{T}$ dan $\dot{p}$ masing-masing adalah laju perubahan suhu dan tekanan udara terhadap waktu, $\propto$ adalah volume spesifik gas (dalam $\mathrm{L}$ ), $C_{p}$ adalah kapasitas panas pada tekanan tetap dan $K=\frac{\gamma-1}{\gamma} \operatorname{dimana} \gamma=\frac{C_{p}}{C_{v}} \operatorname{dimana} C_{v}$ adalah kapasitas panas pada volume tetap. 


\section{2 Model Konsentrasi Gas $\mathrm{CO}_{2}$ di Atmosfer}

Model matematika yang menggambarkan perubahan konsentrasi oksigen di atmosfer diadopsi dari (Sutimin, 2010). Model tersebut dikonstruksi dari persamaan logistik dan persamaan Michaelis-Menten yang berbentuk persamaa diferensial tak linier. Persamaan pembangun model disusun berdasarkan faktor produksi dan konsumsi gas $\mathrm{CO}_{2}$ sebagai berikut :

$$
\dot{x}=b x(1-c x)-\frac{e x}{1+x}
$$

dengan $x$ adalah konsentrasi gas $\mathrm{CO}_{2}$ dan $\dot{x}$ menyatakan laju perubahan konsentrasi gas $\mathrm{CO}_{2}$ terhadap waktu, sedangkan $b, c$ dan $e$ ditentukan berdasarkan data dari (Jorgensen, 1996).

\section{3 Kombinasi Model}

Keterkaitan secara dinamis antara suhu sebagai salah satu unsur utama iklim dengan tekanan udara sebagai unsur utama iklim lainnya dalam penelitian ini dianggap dipengaruhi oleh perubahan konsentrasi gas $\mathrm{CO}_{2}$ di atmosfer. Mengingat secara thermodinamik suhu sebanding dengan tekanan udara dan peningkatan konsentrasi gas $\mathrm{CO}_{2}$ akan mengakibatkan kenaikan suhu maka relasi antara suhu, tekanan udara dan konsentrasi gas $\mathrm{CO}_{2}$ dapat dinyatakan sebagai berikut :

$$
T=x p
$$

Selanjutnya persamaan (4) digunakan dalam menentukan kombinasi system yang dibangun oleh persamaan (1), persamaan (2) dan persamaan (3) sebagai berikut :

III.3.1 Kombinasi I

$\dot{T}=\frac{\dot{q}\left[\alpha p \dot{q}+C_{p}-x p \dot{q}\right]}{C_{p}\left[C_{p}-K \alpha-\dot{q}\right]}$

$\dot{p}=\frac{\dot{q}[K-p \dot{q}]}{\left[c_{p}-K \propto-\dot{q}\right]}$

$\dot{x}=b x(1-c x)-\frac{e x}{1+x}$

III.3.2 Kombinasi II

$\dot{T}=\frac{\dot{q}\left[\alpha p \dot{q}+C_{p}-T \dot{q}\right]}{C_{p}\left[C_{p}-K \propto-\dot{q}\right]}$

$\dot{p}=\frac{\dot{q}[K-p \dot{q}]}{\left[c_{p}-K \propto-\dot{q}\right]}$

$\dot{x}=b-b c\left(\frac{T}{P}\right)-e+\left(b-b c\left(\frac{T}{P}\right)\right) x$

III.3.3 Kombinasi III

$\dot{T}=\frac{\dot{q}\left[\propto\left(\frac{T}{x}\right) \dot{q}+C_{p}-T \dot{q}\right]}{C_{p}\left[C_{p}-K \propto-\dot{q}\right]}$

$\dot{p}=\frac{\dot{q}[K-p \dot{q}]}{\left[c_{p}-K \propto-\dot{q}\right]}$

$\dot{x}=b x(1-c x)-\frac{e x}{1+x}$

III.3.4 Kombinasi IV

$\dot{T}=\frac{\dot{q}\left[\alpha p \dot{q}+C_{p}-T \dot{q}\right]}{C_{p}\left[C_{p}-K \propto-\dot{q}\right]}$

$\dot{p}=\frac{\dot{q}\left[K-\left(\frac{T}{x}\right) \dot{q}\right]}{\left[C_{p}-K \alpha-\dot{q}\right]}$ 
$\dot{x}=b x(1-c x)-\frac{e x}{1+x}$

III.3.5 Kombinasi $\mathrm{V}$

$\dot{T}=\frac{\dot{q}\left[\alpha p \dot{q}+C_{p}-T \dot{q}\right]}{C_{p}\left[C_{p}-K \alpha-\dot{q}\right]}$

$\dot{p}=\frac{\dot{q}[K-p \dot{q}]}{\left[C_{p}-K \propto-\dot{q}\right]}$

$\dot{x}=b\left(\frac{T}{p}\right)(1-c x)-\frac{e x}{1+x}$

\section{4 Pengamatan Kemunculan Parameter}

Kemunculan parameter penentu kestabilan system diperoleh dengan mengamati kestabilan masing-masing sistem di sekitar titik-titik kritis melalui pengamatan terhadap kestabilan linearisasi sistem dengan menentukan nilai eigen matriks jacobian sistem untuk suatu titik kritis tertentu. Sistem dikatakan stabil bila bagian real dari nilai eigen matriks Jacobian suatu sistem bernilai negatif. Titik kritis ditentukan pada kondisi dimana laju perubahan suhu, tekanan udara dan konsentrasi gas $\mathrm{CO}_{2}$, yakni persamaan (5), (6) dan (7) pada masing-masing kombinasi, tidak mengalami perubahan. Syarat yang harus dipenuhi oleh parameter tersebut suatu agar suatu sistem stabil di sekitar titik kritisnya disajikan dalam tabel berikut :

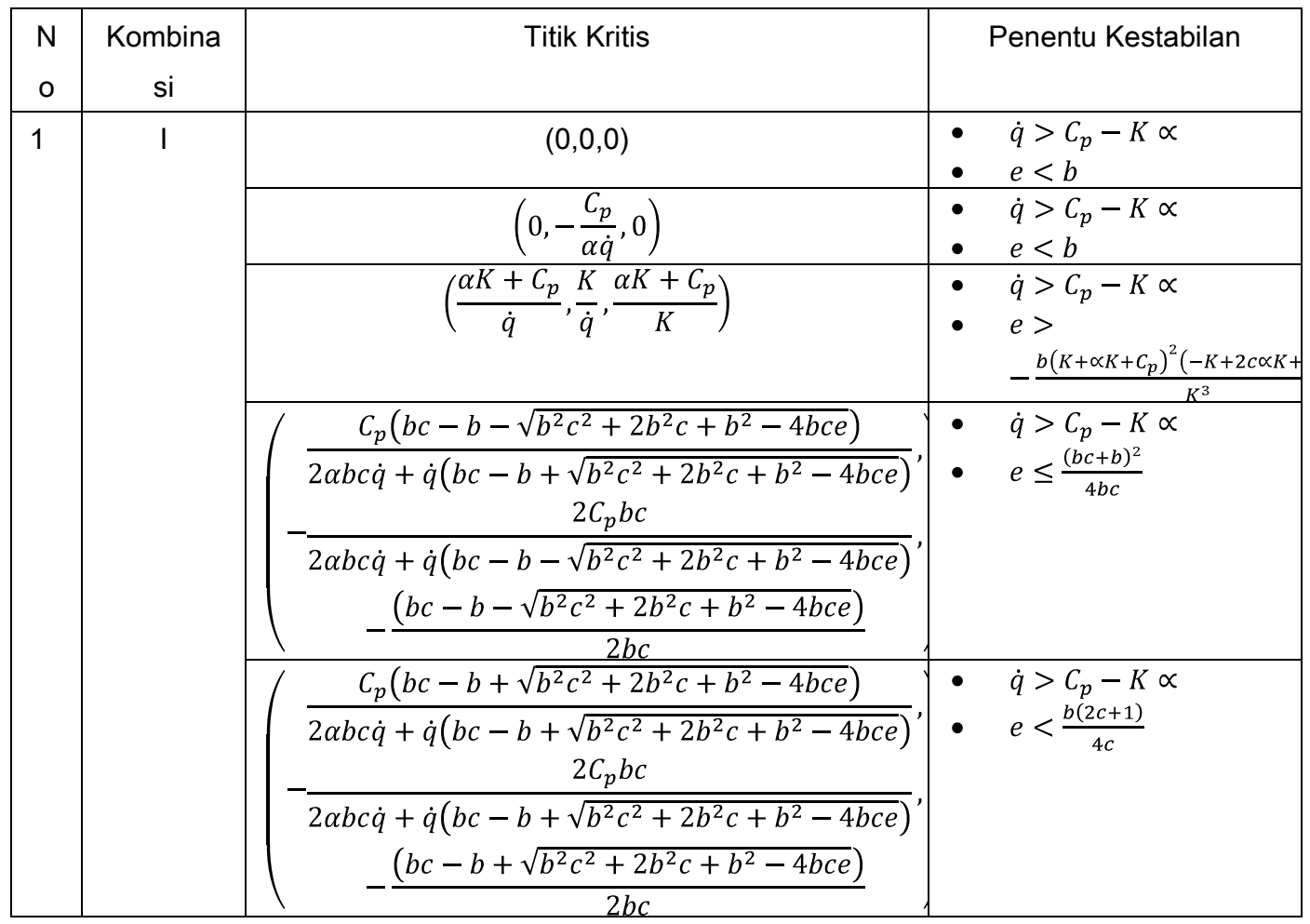




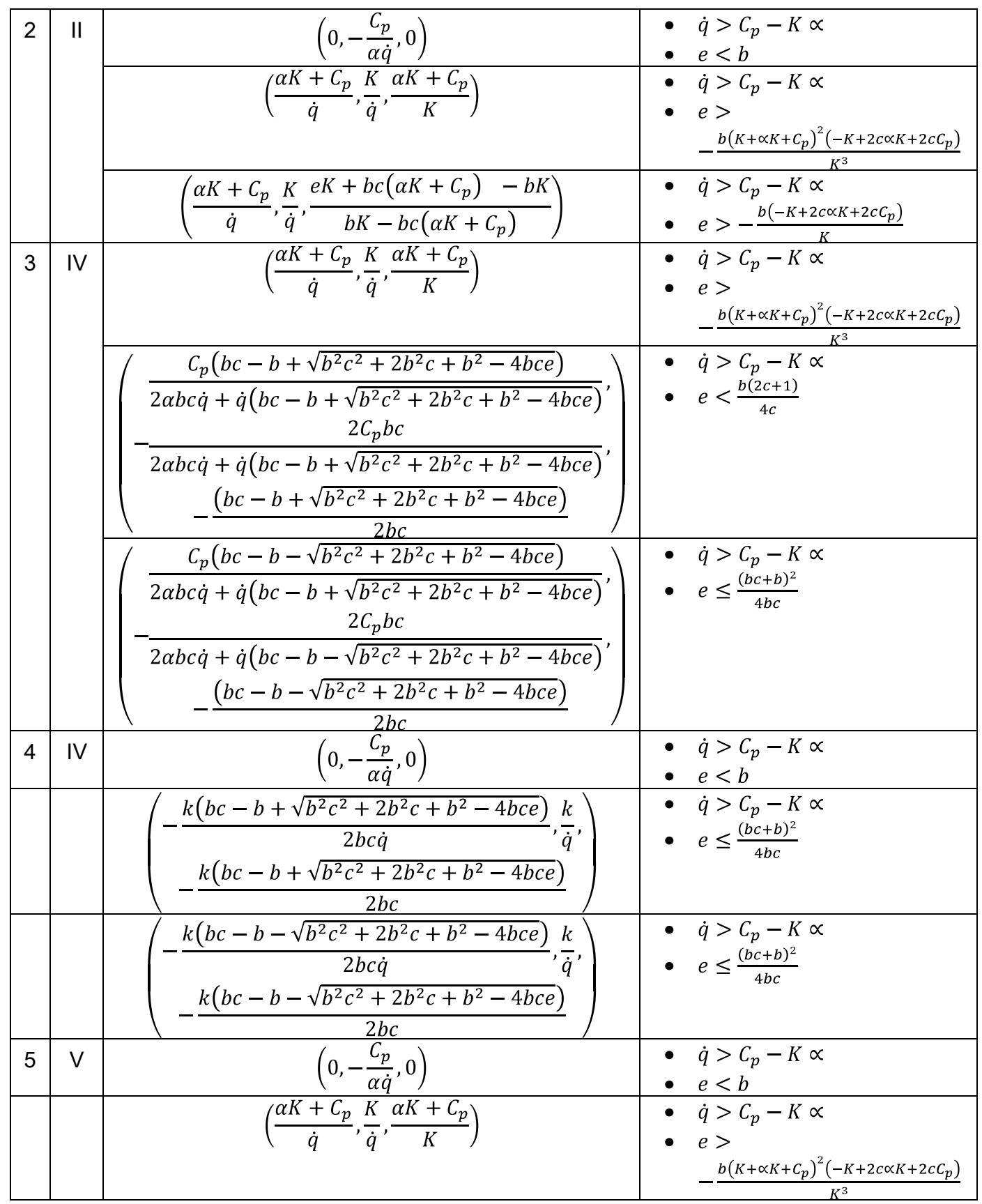

\section{Kesimpulan}

Dari lima kombinasi yang diamati pada penelitian ini dapat disimpulkan bahwa perluasan sistem memunculkan dua buah syarat yang harus dipenuhi oleh dua buah parameter penentu kestabilan sistem. Kedua parameter tersebut adalah laju perubahan kalor $(\dot{q})$ dan tingkat 
produksi gas $\mathrm{CO}_{2}(e)$ yang berkaitan erat dengan tingkat konsumsinya $(b)$. Perubahan kalor harus melebihi suatu nilai yang dinyatakan dalam fungsi kapasitas panas pada tekanan tetap. Sedangkan tingkat konsumsi gas $\mathrm{CO}_{2}$ disyaratkan untuk melebihi tingkat produksi. Hal ini memberikan arti bahwa pengendalian sistem dapat ditempuh melalui pengendalian terhadap kedua parameter tersebut. Hasil ini sesuai dengan kondisi nyata bahwa peningkatan produksi gas $\mathrm{CO}_{2}$ di bumi harus senantiasa diiringi dengan usaha mereduksi kandungan gas $\mathrm{CO}_{2}$ di atmosfer, salah satunya dikenal sebagai reboisasi.

\section{Daftar Pustaka}

1. Jaya, Agus Indra, 2010, Peran Penting Laju Perubahan Kalor pada Model dinamik Unsur-Unsur Utama Iklim, Jurnal IImiah Matematika dan Terapan, Volume 7, Halaman 1-6.

2. Boyce, W. E., and Richard, C. D, 1996, Elementary Differential Equations and Boundary Value Problems, Sixth Edition, Wiley, Singapore.

3. Gabriel, J.F., 2001, Fisika Lingkungan, Penerbit Hipokrates, Jakarta,

4. Haneda, 2004, Hubungan Efek rumah kaca, Pemanasan Global dan Perubahan Iklim, http://climatechange.menlh.go.id, diakses 11 Nopember 2008.

5. Jorgensen, S. E, 1996, Fundamental of Ecology Modeling, $2^{\text {nd }}$ edition, Elsevier Science, B.V., Molenwerf 1, Amsterdam, The Netherland.

6. Kato, S, Tri W. H. dan Joko, W., 1998, Dinamika Atmosfer, Penerbit ITB, Bandung.

7. Lakitan, B., 2002, Dasar-Dasar Klimatologi, PT Raja Grafindo Persada, Jakarta.

8. Leon, S. J., 2001, Aljabar Linier dan Aplikasinya, Edisi 5, (Terjemahan), Penerbit Erlangga, Jakarta.

9. Mudiyarso, D., 2003, Konvensi Perubahan Iklim, Penerbit Buku Kompas, Jakarta.

10. Neiburger, M., James, G. E. dan Bonner W. D., 1995, Memahami Lingkungan Atmosfer Kita, (Terjemahan), Penerbit ITB, Bandung.

11. Sarvina, Ii, 2009, Model dinamik Suhu dan Tekanan Udara Permukiman dengan Menijau Perilaku gas $\mathrm{CO}_{2}$ di Atmosfer sebagai Efek Gas Ruma Kaca, Universitas Tadulako, Palu. 
12. Soedomo, M., 2001, Pencemaran Udara, Kumpulan Karya Ilmiah, Penerbit ITB, Bandung.

13. Sutimin, 2010, Model Matematika Konsentrasi Gas Oksigen Terlarut pada Ekosistem Perairan Danau, Universitas Diponegoro, Semarang

14. Tjasyono, B., 2004, Klimatologo, Penerbit ITB, Bandung.

15. Wikipedia Bahasa Indonesia Ensiklopedia Bebas, 2008, Karbondioksida, http://id.wikipedia.org/wiki/Pemanasan_global, diakses 11 September 2008.

16. 2008, Pemanasan

Global,

http://id.wikipedia.org/wiki/Pemanasan_global, diakses 7 September 2008. 